\title{
Uso do clorofilômetro no manejo da adubação nitrogenada do capim marandu e do capim mombaça
}

\author{
Ana Karina Dias Salman ${ }^{1 *}$, Betânia Maria Filha Soares Bacelar², Enrique Anastácio \\ Alves ${ }^{1}$, Pedro Gomes da Cruz ${ }^{1}$, Angelo Mansur Mendes ${ }^{1}$, Giovanna Araújo de Carvalho ${ }^{3}$ \\ ${ }^{I}$ Pesquisador(a) Empresa Brasileira de Pesquisa Agropecuária (Porto Velho, Rondônia, Brasil - ana.salman@embrapa.br, \\ enrique.alves@embrapa.br; pedro-gomes.cruz@embrapa.br; angelo.mansur@embrapa.br) \\ ${ }^{2}$ Mestra em Desenvolvimento Regional e Meio Ambiente, Porto Velho, Rondônia, Brasil: betaniabacelar@hotmail.com \\ ${ }^{3}$ Zootecnista, Faculdades Integradas Aparício Carvalho - FIMCA, Porto Velho, Rondônia, Brasil: \\ giovanna.carvalhozootec@gmail.com \\ *Autor para correspondência
}

RESUMO. Com o objetivo de avaliar Índices de Suficiência de Nitrogênio (ISN) como critério de manejo da adubação nitrogenada (N) parcelada das forrageiras Brachiaria brizantha $\mathrm{cv}$. Marandu e Panicum maximum cv. Mombaça, foram realizados dois ensaios, um para cada capim, em vasos de $14 \mathrm{dm}^{3}$ preenchidos com Latossolo Vermelho-Amarelo com horizonte (A) húmico sob condições ambientais utilizando delineamento experimental inteiramente casualizado com sete tratamentos definidos de acordo com SNI: referência (REF), testemunha (TEST), 0,96 (T1); 0,93 (T2); 0,90 (T3); 0,87 (T4) e 0,83 (T4), com quatro repetições cada, totalizando 28 parcelas por ensaio. No tratamento REF as parcelas receberam a dose de $133,34 \mathrm{~kg}$ de $\mathrm{N} /$ ha dividida em duas aplicações, a primeira no $1^{\circ} \mathrm{Dia}$ do Período Experimental (DPE) e a segunda após o primeiro corte de avaliação ( $\left.28^{\circ} \mathrm{DPE}\right)$. As parcelas TEST não foram adubadas com N. Nos demais tratamentos, as parcelas foram adubadas ao longo do período experimental somente quando o ISN calculado das parcelas se apresentavam com valores menores que os ISN estabelecidos como critério para adubação. Sendo assim, ao final do experimento, as quantidades totais de N (kg N/ha) utilizadas nos tratamentos T1, T2, T3, T4 e T5 foram, respectivamente: 160,00;80,00; 120,$00 ; 80,00$ e 80,00 (Marandu); e 133,34; 0,00; 120,00; 80,00 e 80,00 (Mombaça). As forrageiras foram avaliadas com idades de rebrote de 51 e 43 dias (correspondentes ao $28^{\circ}$ e $\left.70^{\circ} \mathrm{DPE}\right)$ para: altura de corte $(\mathrm{cm})$, produção de matéria seca ( $\left.\mathrm{kg} \mathrm{MS} / \mathrm{vaso}\right)$ de parte aérea (PMSPA), de raiz (PMSR) e total (PMST); PMSPA acumulada nos dois cortes, relação PMSPA/PMSR e eficiência de conversão do $\mathrm{N}$ fertilizante em PMSPA. O ajuste da adubação nitrogenada dos capins Marandu e Mombaça com base no ISN permitiu que as forrageiras se expressassem de forma semelhante entre os tratamentos em termos de altura de corte e PMSPA acumulada. Em relação à PMSR, observou-se menor produção nas parcelas TEST não adubadas, o que teve reflexo sobre a PMST e na relação PMSPA/PMSR. Concluiu-se que os índices de suficiência de nitrogênio (ISN) mais adequados para ajuste da adubação nitrogenada dos capins Marandu e Mombaça foram, respectivamente, 0,87 e 0,83.

Palavras chave: adubo nitrogenado, forrageiras tropicais, pastagens

\section{Use of chlorophyll meter in the management of nitrogen fertilization of palisade and guinea grasses}

ABSTRACT. Aiming to evaluate Sufficiency Nitrogen Index (SNI) as criteria for
management of nitrogen fertilization of palisade grass (Brachiaria brizantha cv. Marandu)
and guinea grass (Panicum maximum cv. Mombaça), two trials (one for each grass) were
carried out using $14-\mathrm{dm}^{3}$ pots filled with soil classified as Red-Yellow Latosol with umbric
A-horizon under environmental conditions. Trials were arranged in a completely
randomized design with seven treatments defined according to SNI: reference (REF),
control (TEST): 0.96 (T1); 0.93 (T2); 0.90 (T3); 0.87 (T4) and 0.83 (T4), with four 
replicates, totalizing 28 parcels per trial. Within REF treatment, parcels were fertilized with $133.34 \mathrm{~kg} \mathrm{~N} / \mathrm{ha}$ in two applications, the first was in the 1st Day of the Experimental Period (DEP) and the second was done after the first cut for grass evaluation (28th DEP). The TEST parcels were not fertilized with $\mathrm{N}$. Within the other treatments, parcels were $\mathrm{N}$ fertilized through the experimental period only when the calculated SNI of the parcels were below to the SNI chose as criteria for fertilization. Thus, at the end of the experimental period the total amounts of $\mathrm{N}(\mathrm{kg} \mathrm{N} / \mathrm{ha})$ used in the treatments T1, T2, T3, T4 and T5 were, respectively: $160.00,80.00,120.00,80.00$ and 80.00 (palisade); and 133.34, 0.00, 120.00, 80.00 and 80.00 (Guinea). The grasses were evaluated at the cut ages of 51 and 43 days (related to the 28th and 70th DEP) considering the height at cut (cm), dry matter yield $(\mathrm{kg}$ $\mathrm{DM} /$ pot) of aerial portion (DMYAP), of root (DMYR) and total (TDMY); DMYAP accumulated in two cuts, ratio DMYAP/DMYR and efficiency of $\mathrm{N}$ conversion to DMYAP. The adjustment of $\mathrm{N}$ fertilization of palisade and guinea grasses with SNI basis allowed grasses to express in a similar way in terms of cut height and DMYAP accumulated. In relation to DMYR, lower yield was observed in non-fertilized TEST parcels, which had effect on TDMY and in the ratio DMYAP/DMYR. Considering the efficiency of $\mathrm{N}$ conversion to DMYAP, we conclude that the Sufficiency Nitrogen Indexes (SNIs) more adequate to adjust $\mathrm{N}$ fertilization of palisadegrass and guineagrass were 0.87 and 0.83 , respectively.

Keywords: nitrogen fertilizer, pastures, tropical grasses

\section{Introdução}

O estado de Rondônia ocupa a quarta posição na exportação de carne e oitavo na produção de leite. Com rebanho estimado em mais de 12 milhões de cabeças, o estado ocupa a primeira posição em produção de leite na região Norte. Um dos fatores que tornam a pecuária rondoniense mais competitiva é o fato da mesma ser praticada predominantemente com rebanho criado a pasto.

Nos últimos anos, pressões ambientais e mercadológicas somadas a maior disponibilidade de tecnologia têm incentivado uma mudança de atitude no setor produtivo de carne e leite marcada pela busca de maior produtividade via intensificação (Dias Filho, 2011, Martha Júnior et al., 2012). Neste sentido, a adubação nitrogenada é necessária para manutenção da produtividade de gramíneas, porém, possui custo financeiro elevado, o que muitas vezes inviabiliza o uso de doses apropriadas. Além disso, o comportamento do $\mathrm{N}$ no solo apresenta uma dinâmica complexa, pois está sujeito a perdas por lixiviação, volatilização e imobilização por microrganismos (Werner, 1986). Devido ao fato do teor de clorofila se correlacionar positivamente com o teor de nitrogênio foliar, uma vez que de 50 a $60 \%$ do N contido nas folhas estão nos cloroplastos participando da síntese e da estrutura das moléculas de clorofila (Wood et al., 1993), a utilização do clorofilômetro como ferramenta auxiliar no manejo da adubação nitrogenada vem apresentando resultados positivos em relação à recomendação de $\mathrm{N}$ parcelada com base nas leituras indiretas do teor de clorofila foliar em diversas culturas, incluindo forrageiras (Guimarães et al., 2011, Pariz et al., 2011, Barbieri et al., 2012).

Esse estudo teve o objetivo de avaliar o uso do clorofilômetro portátil como ferramenta no manejo da adubação nitrogenada parcelada das forrageiras Brachiaria brizantha cv. Marandu e Panicum maximum cv. Mombaça em Porto Velho-RO, indicando possíveis índices de suficiência de nitrogênio.

\section{Material e Métodos}

Dois ensaios em vasos ao ar livre foram implantados no campo experimental da Embrapa Rondônia localizado no município de Porto Velho ( $8^{\circ} 47^{\prime} 42^{\prime}$ S e $63^{\circ} 50^{\prime} 45^{\prime}$ W) no período de dezembro de 2013 a julho de 2014. O clima da região é classificado como tropical chuvoso do tipo Aw (Köppen \& Geiger, 1928), com duas estações ("seca" e "chuvosa") bem definidas ao longo do ano. As variações de temperatura, precipitação pluvial e da radiação solar diária durante o período do experimento são observadas nas Figuras 1 e 2.

No primeiro período de avaliação das forrageiras, a temperatura média diária foi de $25,9^{\circ} \mathrm{C}$ com precipitação acumulada de $372,8 \mathrm{~mm}$. No segundo período, a temperatura média diária foi $25,7^{\circ} \mathrm{C}$ com precipitação acumulada $163 \mathrm{~mm}$, indicando transição da estação chuvosa para seca (Figuras 1 e 2). Os dados de precipitação, radiação solar e temperatura foram obtidos em estação 
meteorológica automática de superfície localizada no próprio campo experimental.

Para implantação dos ensaios, foram utilizados vasos com volume de $14 \mathrm{dm}^{3}$, os quais foram preenchidos com solo classificado como Latossolo Vermelho-Amarelo com horizonte (A) húmico, com as seguintes características químicas na camada $0-20 \mathrm{~cm}: \mathrm{pH}$ (água) $=5,2 ;$ matéria orgânica $=83,0 \mathrm{~g} / \mathrm{kg} ; \mathrm{P}=2 \mathrm{mg} / \mathrm{dm}^{3} ; \mathrm{K}=0,51$ mmolc $/ \mathrm{dm}^{3} ; \mathrm{Ca}=3,7 \mathrm{mmolc} / \mathrm{dm}^{3} ; \mathrm{Mg}=1,6$ mmolc $/ \mathrm{dm}^{3}$ e $\mathrm{Al}=8,2 \mathrm{mmolc} / \mathrm{dm}^{3} ; \mathrm{Al}+\mathrm{H}=146,9 ;$ $\mathrm{CTC}=152,71 / \mathrm{dm}^{3} \mathrm{e} \mathrm{V}=4 \%$.

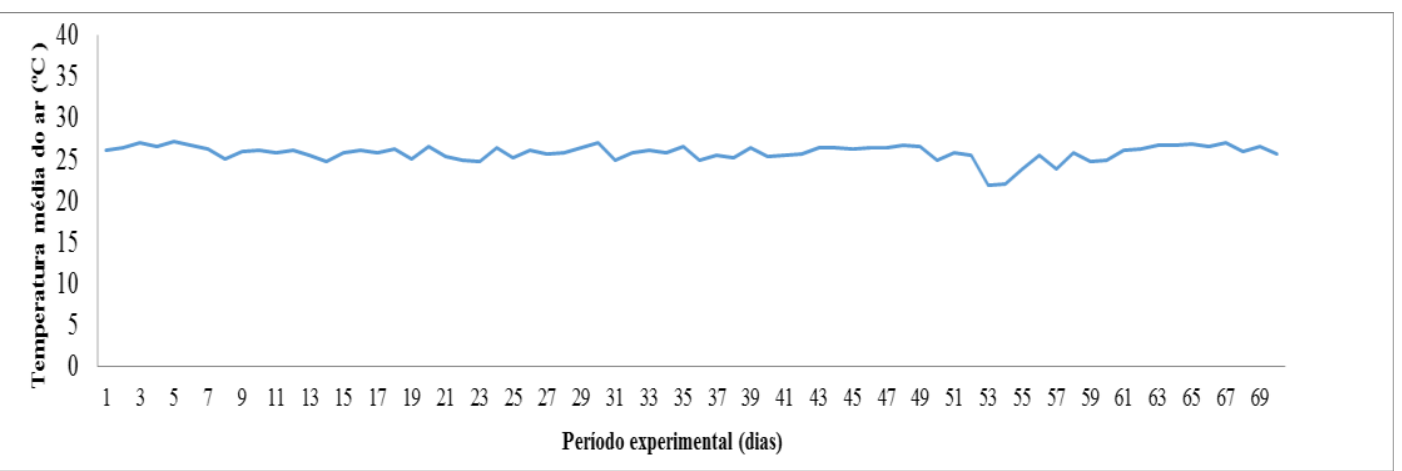

Figura 1. Variação da temperatura média do ar $\left({ }^{\circ} \mathrm{C}\right)$ ao longo do período experimental.

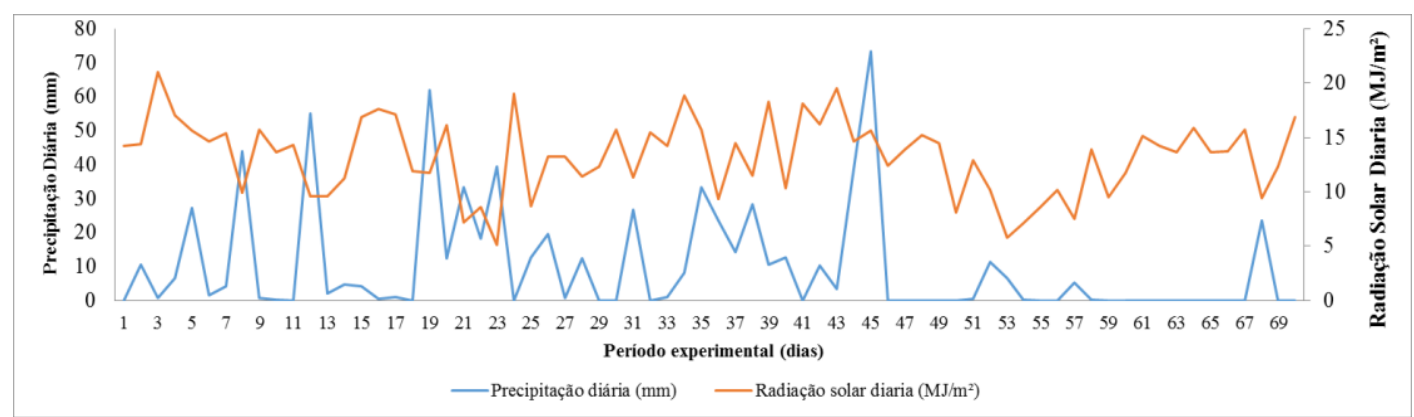

Figura 2: Precipitação pluvial diária $(\mathrm{mm})$ e radiação solar diária $\left(\mathrm{MJ} / \mathrm{m}^{2}\right)$ durante o período experimental.

Quinze dias antes da semeadura, com base no resultado da análise química do solo, foi feita a correção com calcário PRNT 70\% para elevar a saturação por base (V) para $50 \%$, nesse caso utilizou-se 4 ton/ha (0,31 g/vaso). A adubação de base para plantio do capim Marandu foi feita utilizando-se $80 \mathrm{~kg}$ de $\mathrm{P}_{2} \mathrm{O}_{5} / \mathrm{ha}(2,8 \mathrm{~g} / \mathrm{vaso}) ; 80 \mathrm{~kg}$ de $\operatorname{KCL}(0,93 \mathrm{~g} /$ vaso) e $20 \mathrm{~kg}$ FTE (0,14 g/vaso). No caso do capim Mombaça, aplicou-se $120 \mathrm{~kg}$ de $\mathrm{P}_{2} \mathrm{O}_{5} / \mathrm{ha}$ (4,2 g/vaso); $120 \mathrm{~kg}$ de $\mathrm{KCL}$ (1,4 g/vaso) e $20 \mathrm{~kg}$ FTE (0,14 g/vaso). Quarenta dias após a semeadura, foram aplicados nos vasos com capim Marandu e Mombaça $40 \mathrm{~kg}$ de $\mathrm{P}_{2} \mathrm{O}_{5} / \mathrm{ha}$ (2,8 g/vaso).

As recomendações de calagem e adubação para atender as exigências nutricionais das forrageiras Brachiaria brizantha cv. Marandu e Panicum maximum cv. Mombaça são descritas no Sistema de Produção de Leite para Rondônia (EMBRAPA, 2006). No caso da adubação nitrogenada, a dose recomendada para ambas forrageiras foi de 133,34 $\mathrm{kg}$ de $\mathrm{N} / \mathrm{ha}(2,10 \mathrm{~g}$ de ureia/vaso), a qual foi fracionada e aplicada em duas parcelas iguais de $66,7 \mathrm{~kg}$ de $\mathrm{N} / \mathrm{ha}$ (1,05 g de ureia/vaso) nas parcelas de "referência" de ambos os ensaios.

$\mathrm{Na}$ semeadura, as sementes de ambas forrageiras foram depositadas no solo a profundidade de três centímetros. Após a germinação, novas sementes foram aplicadas com o objetivo de uniformizar a densidade de plantio em seis perfilhos por vaso. $\mathrm{O}$ corte de uniformização foi realizado a $10 \mathrm{~cm}$ da superfície do solo 55 dias após a semeadura dos capins.

O delineamento experimental utilizado nos dois ensaios foi o inteiramente casualizado com sete tratamentos e quatro repetições, totalizando 28 parcelas por ensaio.

\section{Os tratamentos foram:}

Testemunha - TEST: não recebeu a adubação nitrogenada;

Referência - REF: adubação nitrogenada com $100 \%$ da dose recomenda; 
Tratamento 1 - T1: adubação nitrogenada na dose equivalente a $30 \%$ da recomendação quando o Índice de Suficiência de Nitrogênio (ISN) < 0,96;

Tratamento 2 - T2: adubação nitrogenada na dose equivalente a $30 \%$ da recomendação quando o Índice de Suficiência de Nitrogênio (ISN) < 0,93;

Tratamento 3 - T3: adubação nitrogenada na dose equivalente a $30 \%$ da recomendação quando o Índice de Suficiência de Nitrogênio (ISN) < 0,90;

Tratamento 4 - T4: adubação nitrogenada na dose equivalente a $30 \%$ da recomendação quando o Índice de Suficiência de Nitrogênio (ISN) < 0,87;

Tratamento 5 - T5: adubação nitrogenada na dose equivalente a $30 \%$ da recomendação quando o Índice de Suficiência de Nitrogênio (ISN) < 0,83.

Ao longo do trabalho, os tratamentos que receberam adubação nitrogenada de acordo com ISN pré-estabelecido (tratamentos de 1 a 5) são denominados de "tratamento ISN".

$\mathrm{O}$ período experimental iniciou-se com as leituras do Índice de Clorofila Foliar (ICF) em ambos os ensaios, 90 dias após a semeadura dos capins e 23 dias após o primeiro corte de uniformização. Foram realizados dois períodos de avaliação de 28 dias com um intervalo de 15 dias, totalizando um período de 70 dias. O primeiro período de avaliação compreendeu do $1^{\circ}$ ao $28^{\circ}$ dia do período experimental (DPE) e o segundo do $43^{\circ}$ ao $70^{\circ}$ DPE (Figura 3 ).

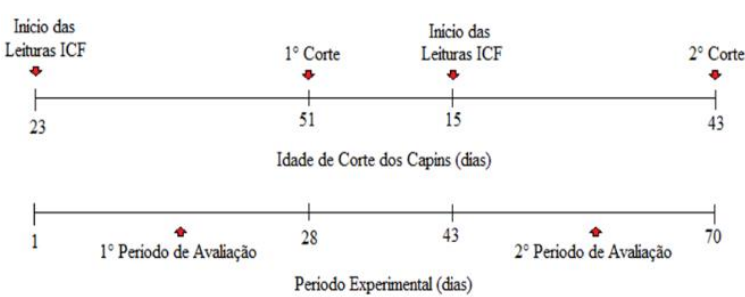

Figura 3. Esquema ensaios realizados indicando o início das leituras do Índice de Clorofila Foliar (IFC), os períodos de avaliação e as idades de corte dos capins (em dias).

Durante os dois períodos de avaliação, em ambos os ensaios, as leituras do ICF foram realizadas diariamente as 9:00 da manhã na folha mais nova completamente expandida de diferentes perfilhos na posição do terço médio da lâmina foliar utilizando-se clorofilômetro digital (CFL 1030 - Falker). As folhas foram posicionadas entre o emissor e o receptor do equipamento, de modo que a radiação transmitida através da folha fosse convertida em sinais eletrônicos (Figura 4). A média diária de cada parcela foi calculada com base em 10 leituras dos valores ICF.

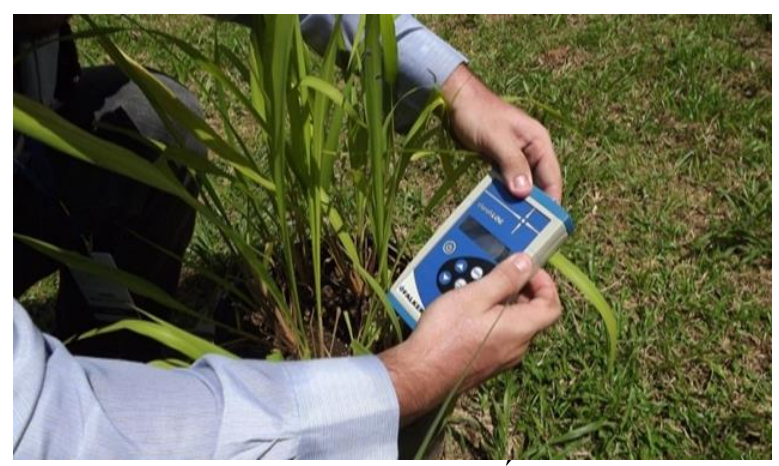

Figura 4. Leitura dos valores do Indice de Clorofila Foliar (IFC) no terço médio da folha utilizando o clorofilômetro portátil (CFL 1030 - Falker®). (Foto: Betânia M.F.S. Bacelar).

A leitura do Índice de Clorofila Foliar (ICF) no tempo zero (L0) foi realizada antes da aplicação da primeira dose de nitrogênio nas parcelas de referência, que correspondeu ao $1^{\circ}$ dia do período experimental (DPE). Imediatamente após L0, aplicou-se a primeira parcela da adubação nitrogenada nos vasos referência $(1,05 \mathrm{~g}$ de ureia/vaso). Nesse mesmo dia, os cinco tratamentos ISN (T1, T2, T3, T4 e T5) receberam $30 \%$ da dose de $\mathrm{N}$ recomendada para cada forrageira, que correspondeu a $0,63 \mathrm{~g}$ de ureia/vaso.

O cálculo do Índice de Suficiência de Nitrogênio (ISN) de cada um dos cinco tratamentos ISN também foi realizado diariamente durante os dois períodos de avaliação em ambos os ensaios utilizando planilhas do Excel ${ }^{\circledR}$. O ISN calculado $\left(\mathrm{INS}_{\text {calc }}\right)$ é a relação entre os valores ICF de cada tratamento (ICF-T) e os valores ICF da referência (ICF-R), dada pela equação $\mathrm{INS}_{\text {calc }}=$ ICF-T/ICF-R, de acordo com a metodologia proposta por (Francis \& Piekielek, 1999). Semanalmente, calculava-se a média dos ISN $\mathrm{Salc}_{\text {calc }}$ dos tratamentos e quando esta apresentava-se inferior ao ISN adotado como critério para adubação nitrogenada em cada tratamento $(\mathrm{T} 1=$ $0,96, \mathrm{~T} 2=0,93, \mathrm{~T} 3=0,90, \mathrm{~T} 4=0,87$ e $\mathrm{T} 5=0,83$ ) foi aplicada $30 \%$ da dose de $\mathrm{N}$ recomendada para cada forrageira $(0,63 \mathrm{~g}$ de ureia/vaso) (Tabela 1$)$.

No ensaio com capim Marandu, observou-se necessidade de adubação das parcelas dos tratamentos $\mathrm{T} 1$ e $\mathrm{T} 3$ no $16^{\circ}$ dia do período experimental (DPE); no $23^{\circ}$ DPE foi necessário fazer nova adubação nas parcelas do T1. No $48^{\circ}$ DPE do segundo período de avaliação, foi feita a adubação de todos os tratamentos e no $65^{\circ} \mathrm{DPE}$ 
não foi necessário fazer a adubação nitrogenada em nenhum dos tratamentos. Em relação ao capim Mombaça, no $16^{\circ}$ DPE observou-se necessidade de adubação das parcelas do T1; no $23^{\circ} \mathrm{DPE}$ foram adubadas as parcelas do T2. No segundo período de avaliação, as parcelas de todos os tratamentos $48^{\circ} \mathrm{DPE}$ e no $65^{\circ} \mathrm{DPE}$ não houve indicação de adubação em nenhum dos tratamentos (Tabela 1).

Tabela 1. Médias semanais dos Índices de Suficiência de Nitrogênio calculados (ISN calc) para cada tratamento nos ensaios com capim Marandu e Mombaça.

\begin{tabular}{lcccc}
\hline \multicolumn{5}{c}{ Brachiaria brizantha cv. Marandu } \\
\hline \multirow{5}{*}{ Tratamento } & 16 & 23 & 48 & 65 \\
\cline { 2 - 5 } & 0,93 & 0,94 & 0,87 & 1,09 \\
\hline (ISN: 0,96) & 0,94 & 0,96 & 0,85 & 1,05 \\
2 (ISN: 0,93) & 0,89 & 0,90 & 0,85 & 1,05 \\
3 (ISN: 0,90) & 0,95 & 0,92 & 0,85 & 1,04 \\
4 (ISN: 0,87) & 0,91 & 0,88 & 0,79 & 1,05 \\
\hline (ISN: 0,83) & Panicum maximum cv. Mombaça & \\
\hline & \multicolumn{5}{c}{ Período Experimental (dias) } \\
\hline & 16 & 23 & 48 & 65 \\
\hline (ISN: 0,96) & 0,95 & 0,93 & 1,09 & 1,11 \\
2 (ISN: 0,93) & 0,98 & 0,91 & 1,05 & 1,07 \\
3 (ISN: 0,90) & 0,99 & 0,94 & 1,05 & 1,10 \\
4 (ISN: 0,87) & 0,94 & 0,92 & 1,04 & 1,05 \\
5 (ISN: 0,83) & 0,94 & 1,00 & 1,05 & 1,10 \\
\hline
\end{tabular}

Na Tabela 2 é apresentada a quantidade de ureia (e seu equivalente em nitrogênio) aplicada ao longo de todo período experimental nas parcelas de cada tratamento de ambos os ensaios. No $1^{\circ}$ dia do período experimental (DPE) ocorreu a adubação nitrogenada dos vasos referência $(1,05$ $\mathrm{g}$ de ureia/vaso), assim como a adubação inicial de todos os tratamentos com $0,63 \mathrm{~g}$ de ureia/vaso. A segunda dose de $\mathrm{N}$ aplicada vasos referência $(1,05$ $\mathrm{g}$ de ureia/vaso) ocorreu no $28^{\circ} \mathrm{DPE}$, logo após o primeiro corte de avaliação.

Ao final de cada período de avaliação e antes dos cortes de avaliação das forrageiras, foi medida a altura total $(\mathrm{em} \mathrm{cm})$ dos capins utilizando-se régua graduada em cinco plantas escolhidas aleatoriamente por vaso.

A produção de matéria seca da parte aérea (PMSPA) em cada parcela foi determinada após o corte das plantas a $10 \mathrm{~cm}$ do solo (altura definida para os dois capins), seguindo-se de pesagem em balança semianalítica e secagem em estufa de ventilação forçada de ar a $65^{\circ} \mathrm{C}$ até peso constante. Posteriormente, essas amostras foram moídas a 1 $\mathrm{mm}$ em moinho tipo Willey para envio ao Laboratório de Solos e Análise de Plantas da Embrapa Rondônia, onde determinou-se a matéria seca em estufa a $105^{\circ} \mathrm{C}$ por 72 horas.

Tabela 2. Quantidade de ureia (e seu equivalente em $\mathrm{kg}$ de $\mathrm{N}$ por ha) aplicada ao longo de todo período experimental nas parcelas de cada tratamento dos ensaios com os capins Marandu e Mombaça.

\begin{tabular}{|c|c|c|c|c|c|c|c|c|}
\hline \multicolumn{9}{|c|}{ Capim Marandu } \\
\hline \multirow{2}{*}{ Tratamentos } & \multicolumn{6}{|c|}{ Período experimental (dias) } & \multirow{2}{*}{$\begin{array}{r}\text { Total (g de } \\
\text { ureia/vaso) }\end{array}$} & \multirow{2}{*}{$\begin{array}{l}\text { Total (k } \\
\text { de N/ha }\end{array}$} \\
\hline & 1 & 16 & 23 & 28 & 48 & 65 & & \\
\hline Referência & 1,05 & 0 & 0 & 1,05 & 0 & 0 & 2,10 & 133,34 \\
\hline Testemunha & 0 & 0 & 0 & 0 & 0 & 0 & 0 & 0 \\
\hline 1 (ISN: 0,96) & 0,63 & 0,63 & 0,63 & 0 & 063 & 0 & 2,52 & 160,00 \\
\hline 2 (ISN: 0,93) & 0,63 & 0 & 0 & 0 & 0,63 & 0 & 1,26 & 80,00 \\
\hline 3 (ISN: 0,90) & 0,63 & 0,63 & 0 & 0 & 0,63 & 0 & 1,89 & 120,00 \\
\hline 4 (ISN: 0,87) & 0,63 & 0 & 0 & 0 & 0,63 & 0 & 1,26 & 80,00 \\
\hline 5 (ISN: 0,83) & 0,63 & 0 & 0 & 0 & 0,63 & 0 & 1,26 & 80,00 \\
\hline \multicolumn{9}{|c|}{ Capim Mombaça } \\
\hline \multirow{2}{*}{ Tratamentos } & \multicolumn{6}{|c|}{ Período experimental (dias) } & Total (g de & Total $(\mathrm{kg}$ \\
\hline & 1 & 16 & 23 & 28 & 48 & 65 & ureia/vaso) & de N/ha) \\
\hline Referência & 1,05 & 0 & 0 & 1,05 & 0 & 0 & 2,10 & 133,34 \\
\hline Testemunha & 0 & 0 & 0 & 0 & 0 & 0 & 0 & 0 \\
\hline 1 (ISN: 0,96) & 0,63 & 0,63 & 0 & 0 & 0,63 & 0 & 1,89 & 120,00 \\
\hline 2 (ISN: 0,93) & 0,63 & 0 & 0,63 & 0 & 0,63 & 0 & 1,89 & 120,00 \\
\hline 3 (ISN: 0,90) & 0,63 & 0 & 0 & 0 & 0,63 & 0 & 1,26 & 80,00 \\
\hline 4 (ISN: 0,87) & 0,63 & 0 & 0 & 0 & 0,63 & 0 & 1,26 & 80,00 \\
\hline 5 (ISN: 0,83 ) & 0,63 & 0 & 0 & 0 & 0,63 & 0 & 1,26 & 80,00 \\
\hline
\end{tabular}

Ao final do experimento, as raízes foram separadas do solo e lavadas em água corrente para retirada de sujidades. Em seguida, foram acondicionadas em sacos de papel e pesadas em balança semianalítica. Imediatamente após a pesagem, as amostras foram secas em estufa com circulação forçada de ar a $65^{\circ} \mathrm{C}$ até peso constante. Após a secagem, as mesmas foram pesadas para determinação da produção de matéria seca de raiz (PMSR).

A produção acumulada de matéria seca da parte aérea foi obtida somando-se a PMSPA dos dois cortes de avaliação das forrageiras. A produção de 
matéria seca total (PMST) foi obtida somando-se a PMSPA com a PMSR.

A eficiência de conversão do nitrogênio aplicado via fertilizante (ureia) em matéria seca da parte aérea (PMSPA) foi obtida através da relação entre a PMSPA $(\mathrm{kg})$ e a quantidade total de N adicionado na parcela $(\mathrm{kg})$.

As análises estatísticas das variáveis avaliadas (altura do capim, PMSPA, PMSR, PMST, eficiência de conversão do $\mathrm{N}$ fertilizante em MS da parte aérea) foram realizadas utilizando o programa livre Assistat 7.7 beta. A análise de variância foi realizada pelo procedimento ANOVA e a comparação das médias foi feita pelo teste de Tukey a $5 \%$ de probabilidade.

\section{Resultados e Discussão}

Observando as leituras diárias do ICF em ambos os ensaios (Figuras 5 a 8 ) foi possível analisar o comportamento das duas espécies forrageiras em resposta a aplicação ou não do nitrogênio na forma de ureia ao longo dos dois períodos de avaliação.

No primeiro período de avaliação, observou-se que a partir do $5^{\circ}$ Dia do Período Experimental (DPE) as parcelas que não receberam nenhuma dose de adubo nitrogenado (testemunhas) em ambos os ensaios, apresentaram valores de ICF numericamente menores em relação aos demais tratamentos, que receberam adubação nitrogenada, até o $27^{\circ} \mathrm{DPE}$.

Corroborando com os resultados de Costa et al. (2008) que avaliaram área de pastagem estabelecida com capim Marandu submetida à diferentes doses de $\mathrm{N}$ via sulfato de amônio ou ureia no período de três anos, e observaram que a adubação com 100, 200 e $300 \mathrm{~kg}$ de N/ha/ano proporcionaram aumento de 27,28 e $30 \%$ nos teores de clorofila foliar (valores médios de SPAD de 44,23; 45,03 e 46,14, respectivamente) em relação as parcelas não adubadas (média de SPAD de 32,00).

Em relação ao comportamento das parcelas "referência", ressalta-se que os maiores valores de ICF ocorreram no $11^{\circ} \mathrm{DPE}$, que foram 48,44 e 40,75, observados nos capins Marandu e Mombaça, respectivamente. Silva Júnior (2013), avaliando o teor de nitrogênio foliar e os valores SPAD no capim braquiária (Brachiaria decubens) aos 15, 21 e 32 Dias Após a Adubação (DAA) com cinco doses de nitrogênio $(0,50,100,150$ e 200 $\mathrm{kg} / \mathrm{ha}$ ) na forma de ureia, observou que o capim apresentou respostas significativas à adubação nitrogenada a partir de 15 DAA, apresentando maior correlação entre o valor de SPAD e o N foliar aos 21 DAA.

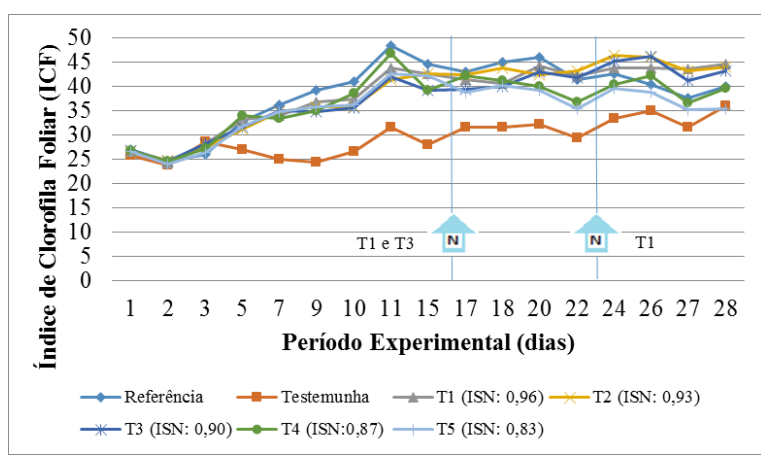

Figura 5. Comportamento do ICF do capim Marandu no $1^{\circ}$ Período de Avaliação.

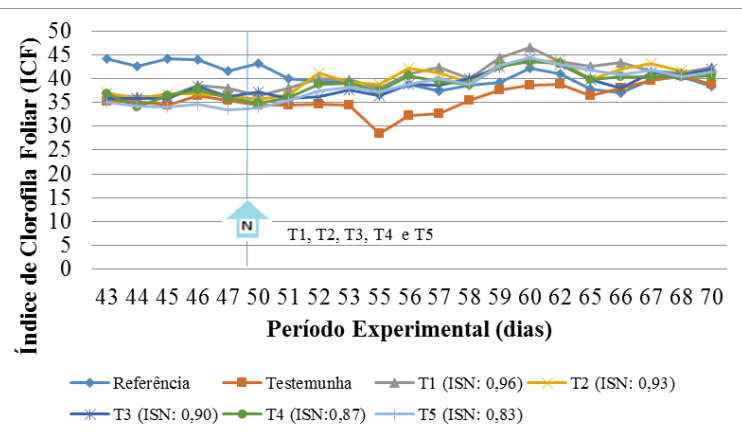

Figura 6. Comportamento do ICF do capim Marandu no $2^{\circ}$ período de avaliação

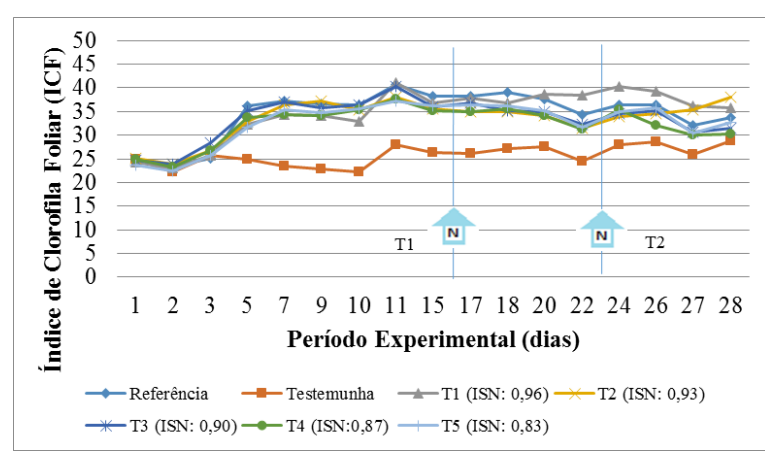

Figura7. Comportamento do ICF do capim Mombaça no $1^{\circ}$ Período de Avaliação.

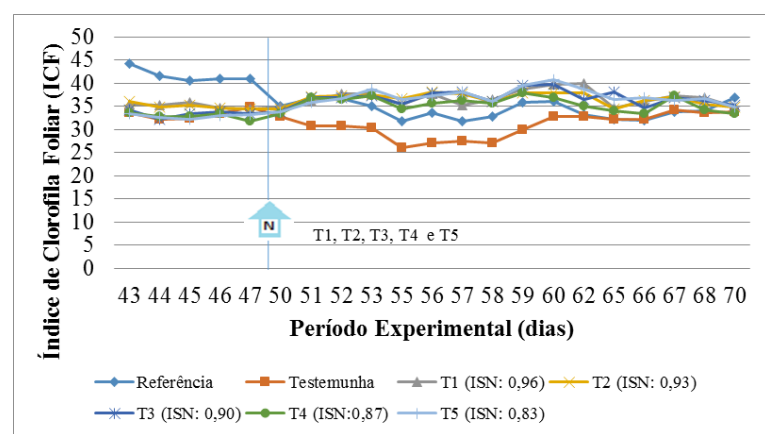

Figura 8. Comportamento do ICF do capim Mombaça no $2^{\circ}$ Período de Avaliação 
Após a aplicação de $30 \%$ da dose de N no $16^{\circ}$ DPE (Tabela 2) nas parcelas dos tratamentos T1 e T3 do ensaio com Marandu e das parcelas do T1

no ensaio com Mombaça, apenas o T1 do ensaio com Mombaça apresentou valor do ICF numericamente maior que os dos demais tratamentos do $22^{\circ}$ ao $26^{\circ}$ DPE (Figuras 5 a 7 ). Ainda no primeiro período de avaliação houve a necessidade de aplicação de $30 \%$ da dose de $\mathrm{N}$ nas parcelas do T1 do ensaio com Marandu e do T2 do ensaio com Mombaça no $23^{\circ} \mathrm{DPE}$, observando-se que no T2 do Mombaça ocorreu um aumento de 6,69 unidades no ICF do $23^{\circ}$ ao $28^{\circ}$ DPE. Nesse mesmo período, o aumento do ICF do T1 do Marandu foi de 2,41 unidades. Estes resultados podem indicar talvez uma resposta mais rápida do capim Mombaça a adubação nitrogenada do que o capim Marandu.

No presente estudo esperava-se observar respostas semelhantes dos capins Marandu e Mombaça em termos de ICF após a aplicação em cobertura do nitrogênio na forma de ureia. No entanto, essa resposta parece demorar alguns dias e depende da espécie forrageira. Como os ensaios não foram delineados com a finalidade de avaliar o tempo de resposta dos capins Marandu e Mombaça à adubação nitrogenada, não temos como afirmar que existe uma diferença entre essas duas espécies forrageiras. No entanto, pode-se supor que essas forrageiras respondem em velocidades diferentes à adubação nitrogenada com ureia. Hipótese que pode ser testada em trabalhos futuros.

No segundo período de avaliação, que se iniciou 15 dias após o primeiro corte de avaliação das forrageiras e da adição da segunda parcela da dose de $\mathrm{N}$ nas parcelas de referência, observou-se que os valores do ICF das parcelas de referência de ambos os ensaios foram numericamente maiores em relação aos demais tratamentos até o $50^{\circ}$ DPE (Marandu) e $47^{\circ}$ DPE (Mombaça). E, no caso das testemunhas, em ambos os ensaios, os valores do ICF foram semelhantes aos dos demais tratamentos até o momento em que foi realizada a adubação de todos os tratamentos de ambos os ensaios com $30 \%$ da dose de N no $48^{\circ}$ DPE.

A partir desse momento, as parcelas dos tratamentos adubados de ambos os ensaios apresentaram valores de IFC que se aproximaram dos valores da referência a partir do $51^{\circ}$ (Marandu) e do $50^{\circ}$ (Mombaça) DPE. Com relação aos valores do ICF das testemunhas, esses foram numericamente inferiores aos demais no período entre o $53^{\circ}$ ao $62^{\circ} \mathrm{DPE}$ (Marandu) e entre o $51^{\circ}$ ao $60^{\circ} \mathrm{DPE}$ (Mombaça). A partir do $65^{\circ} \mathrm{DPE}$ em ambos os ensaios, as parcelas de todos os tratamentos (inclusive referências e testemunhas) apresentaram comportamentos em termos de ICF semelhantes (Figuras 6 e 8 ). Para Bullock \& Anderson (1998), com o aumento da disponibilidade de $\mathrm{N}$ para a planta, o teor de clorofila foliar atinge um patamar denominado de ponto de maturidade fotossintético, que se mantém invariável, mesmo com incremento de $\mathrm{N}$ no tecido da planta.

No presente estudo, observou-se que 15 dias após a última adubação com ureia $\left(48^{\circ} \mathrm{DPE}\right)$ todos os tratamentos ISN apresentaram comportamento semelhante em termos de ICF. Esse comportamento se deve ao fato de haver uma relação direta entre o ICF e o teor de $\mathrm{N}$ foliar, e estes em relação ao nível de adubação nitrogenada. Abreu \& Monteiro (1999) observaram uma relação linear direta entre o teor de clorofila (valor SPAD) e a concentração de nitrogênio total nas folhas do capim Marandu cultivado em vaso adubado com diferentes doses de nitrato de amônio $(0,75,150$ e $300 \mathrm{mg} / \mathrm{kg}$ de solo $)$.

Outros estudos também comprovaram a relação entre a adubação nitrogenada e o índice de clorofila foliar medido com clorofilômetro portátil em espécies forrageiras (Benettt et al., 2008, Costa et al., 2008, Maranhão et al., 2009, Pariz et al., 2011, Barbieri Junior et al., 2012), sendo o teor de clorofila foliar altamente correlacionado com o teor de nitrogênio total nas folhas. Dessa forma, é possível inferir que nesse estudo o clorofilômetro portátil foi uma ferramenta adequada para medir as respostas dos capins à adubação nitrogenada.

As médias da produção de matéria seca da parte aérea (PMSPA), da raiz (PMSR) e total (PMST), assim como a razão entre a PMSPA e PMSR e a altura de corte dos capins Marandu e Mombaça estão apresentadas na Tabela 3.

A produção de matéria seca da parte aérea (PMSPA) do capim Marandu apresentou diferença estatística entre a referência $(29,83 \%)$ e a testemunha $(25,1 \%)$ no segundo corte; porém, não foi verificada diferença entre os tratamentos ISN e nem desses em relação à testemunha e a referência. Considerando a produção de matéria seca acumulada nos dois cortes, não foi observada diferença entre as médias de todos os tratamentos tanto no ensaio com Marandu quanto no Mombaça. 
Em relação à altura, o capim Marandu não apresentou diferença estatística entre os tratamentos, mesmo considerando a aplicação de diferentes doses de N. Já o capim Mombaça apresentou diferença estatística entre a referência $(45,75 \mathrm{~cm})$ e a testemunha $(27,50 \mathrm{~cm})$ apenas no segundo corte; porém, não foi verificada diferença entre os tratamentos ISN e nem desses em relação à testemunha e a referência.

Considerando a produção de matéria seca da raiz (PMSR), o capim Marandu apresentou diferença estatística, sendo que na testemunha a
PMSR foi menor em relação à referência e aos demais tratamentos. No T1, tratamento que recebeu a maior dose de $\mathrm{N}(2,52 \mathrm{~g}$ de ureia/vaso), as plantas produziram maior quantidade de MS de raiz $(53,63 \%)$ em relação à testemunha e ao T2 (que recebeu 1,26 $\mathrm{g}$ de ureia/vaso), sendo semelhante à da referência e demais tratamentos. Em relação à PMSR do capim Mombaça, houve diferença estatística apenas para testemunha, que não foi adubada e, portanto, produziu menor quantidade de raízes do que os demais tratamentos que não diferiram entre si.

Tabela 3. Produção de matéria seca parte aérea (PMSPA, g/vaso) no $1^{\circ}$ e $2^{\circ}$ corte e acumulada (soma dos dois cortes), produção de matéria seca de raiz (PMSR, g/vaso), produção de matéria seca total (PMS total, g/vaso), relação parte aérea/raiz e altura $(\mathrm{cm})$ no $1^{\circ}$ e $2^{\circ}$ corte e média dos dois cortes dos capins Marandu e Mombaça.

\begin{tabular}{|c|c|c|c|c|c|c|c|c|c|}
\hline \multicolumn{10}{|c|}{ Brachiaria brizantha $\mathrm{cv}$. Marandu } \\
\hline \multirow{3}{*}{ Tratamento } & \multicolumn{5}{|c|}{ Produção de Matéria Seca (g/vaso) } & \multirow{3}{*}{$\begin{array}{l}\text { Razão Parte } \\
\text { Aérea/Raiz }\end{array}$} & \multirow{2}{*}{\multicolumn{3}{|c|}{ Altura $(\mathrm{cm})$}} \\
\hline & \multicolumn{3}{|c|}{ Parte Aérea (PMSPA) } & \multirow{2}{*}{ Raiz (PMSR) } & \multirow{2}{*}{ Total (PMST) } & & & & \\
\hline & $1^{\circ}$ Corte & $2^{\circ}$ Corte & Acumulada & & & & $1^{\circ}$ Corte & $2^{\circ}$ Corte & Média \\
\hline Referência & $27,88 \mathrm{a}$ & 29,83 a & $57,71 \mathrm{a}$ & $51,79 \mathrm{ab}$ & $109,5 \mathrm{a}$ & $1,13 \mathrm{~b}$ & 43,00 a & $37,00 \mathrm{a}$ & $40,00 \mathrm{a}$ \\
\hline Testemunha & 29,18 a & $25,09 \mathrm{~b}$ & $54,27 \mathrm{a}$ & $23,05 \mathrm{c}$ & $77,32 \mathrm{~b}$ & $2,40 \mathrm{a}$ & $43,50 \mathrm{a}$ & $27,50 \mathrm{a}$ & $35,50 \mathrm{a}$ \\
\hline 1 (ISN: 0,96) & 26,69 a & $28,36 \mathrm{ab}$ & $55,05 \mathrm{a}$ & 53,63 a & $108,7 \mathrm{a}$ & $1,04 \mathrm{~b}$ & $50,00 \mathrm{a}$ & $35,25 \mathrm{a}$ & $42,63 \mathrm{a}$ \\
\hline 2 (ISN: 0,93) & 27,90 a & $27,91 \mathrm{ab}$ & $55,81 \mathrm{a}$ & $38,84 \mathrm{~b}$ & $94,64 \mathrm{ab}$ & $1,45 \mathrm{~b}$ & $48,00 \mathrm{a}$ & $37,00 \mathrm{a}$ & $42,50 \mathrm{a}$ \\
\hline 3 (ISN: 0,90) & $28,52 \mathrm{a}$ & $27,18 \mathrm{ab}$ & $55,71 \mathrm{a}$ & $47,81 \mathrm{ab}$ & $103,52 \mathrm{a}$ & $1,18 \mathrm{~b}$ & $47,25 \mathrm{a}$ & $34,75 \mathrm{a}$ & $41,00 \mathrm{a}$ \\
\hline 4 (ISN: 0,87) & 28,19 a & $27,15 \mathrm{ab}$ & $55,34 \mathrm{a}$ & $42,37 \mathrm{ab}$ & 97,71 a & $1,31 \mathrm{~b}$ & $48,00 \mathrm{a}$ & $34,00 \mathrm{a}$ & $41,00 \mathrm{a}$ \\
\hline 5 (ISN: 0,83) & 29,79 a & $27,51 \mathrm{ab}$ & $57,30 \mathrm{a}$ & $42,04 \mathrm{ab}$ & 99,35 a & $1,42 \mathrm{~b}$ & $43,00 \mathrm{a}$ & $34,00 \mathrm{a}$ & $38,50 \mathrm{a}$ \\
\hline $\mathrm{dms}$ & 6,69 & 3,76 & 9,44 & 14,18 & 18,05 & 0,59 & 15,13 & 10,81 & 9,98 \\
\hline CV\% & 10,28 & 5,94 & 7,35 & 14,42 & 7,96 & 17,97 & 14,28 & 13,75 & 10,82 \\
\hline \multicolumn{10}{|c|}{ Panicum maximum cv. Mombaça } \\
\hline \multirow{3}{*}{ Tratamento } & \multicolumn{5}{|c|}{ Produção de Matéria Seca (g/vaso) } & \multirow{3}{*}{$\begin{array}{l}\text { Razão Parte } \\
\text { Aérea/Raiz }\end{array}$} & \multirow{2}{*}{\multicolumn{3}{|c|}{ Altura $(\mathrm{cm})$}} \\
\hline & \multicolumn{3}{|c|}{ Parte Aérea (PMSPA) } & \multicolumn{2}{|c|}{ Raiz (PMSR) Total (PMST) } & & & & \\
\hline & $1^{\circ}$ Corte & $2^{\circ}$ Corte & Acumulada & $1^{\circ}$ Corte & $2^{\circ}$ Corte & & $1^{\circ}$ Corte & \multicolumn{2}{|c|}{$2^{\circ}$ Corte Média } \\
\hline Referência & $29,39 \mathrm{a}$ & $28,60 \mathrm{a}$ & 57,99 a & $35,08 \mathrm{a}$ & $93,08 \mathrm{a}$ & $1,69 \mathrm{~b}$ & $54,00 \mathrm{a}$ & $45,75 \mathrm{a}$ & $49,88 \mathrm{a}$ \\
\hline Testemunha & 29,79 a & 25,43 a & $55,22 \mathrm{a}$ & $13,87 \mathrm{~b}$ & $69,09 \mathrm{~b}$ & $4,22 \mathrm{a}$ & $49,50 \mathrm{a}$ & $27,50 \mathrm{~b}$ & $38,50 \mathrm{a}$ \\
\hline 1 (ISN: 0,96) & $31,16 \mathrm{a}$ & $26,88 \mathrm{a}$ & $58,05 \mathrm{a}$ & 30,56 a & 88,61 a & $1,94 \mathrm{~b}$ & $49,50 \mathrm{a}$ & $37,50 \mathrm{ab}$ & $43,50 \mathrm{a}$ \\
\hline 2 (ISN: 0,93) & $30,60 \mathrm{a}$ & 29,43 a & $60,03 \mathrm{a}$ & $37,08 \mathrm{a}$ & 97,11 a & $1,70 \mathrm{~b}$ & $50,75 \mathrm{a}$ & $38,50 \mathrm{ab}$ & $44,63 \mathrm{a}$ \\
\hline 3 (ISN: 0,90) & $29,95 \mathrm{a}$ & 31,65 a & $61,60 \mathrm{a}$ & $30,75 \mathrm{a}$ & 92,35 a & $2,07 \mathrm{~b}$ & $50,25 \mathrm{a}$ & $35,50 \mathrm{ab}$ & $42,88 \mathrm{a}$ \\
\hline 4 (ISN: 0,87) & 31,96 a & 27,98 a & $59,94 \mathrm{a}$ & $28,54 \mathrm{a}$ & 88,48 a & $2,19 \mathrm{~b}$ & $51,00 \mathrm{a}$ & $36,25 \mathrm{ab}$ & $43,63 \mathrm{a}$ \\
\hline 5 (ISN: 0,83) & 29,93 a & $29,21 \mathrm{a}$ & $59,14 \mathrm{a}$ & $33,40 \mathrm{a}$ & $92,54 \mathrm{a}$ & $1,79 \mathrm{~b}$ & $46,50 \mathrm{a}$ & $40,25 \mathrm{ab}$ & $43,38 \mathrm{a}$ \\
\hline $\mathrm{dms}$ & 5,45 & 7,29 & 10,13 & 12,40 & 10,46 & 1,47 & 17,82 & 15,08 & 14,50 \\
\hline$\overline{\mathrm{CV} \%}$ & 7,80 & 11,15 & 7,49 & 18,04 & 5,13 & 28,74 & 15,44 & 17,58 & 14,41 \\
\hline
\end{tabular}

Médias seguidas de letras iguais na coluna não se diferem pelo teste de Tukey a 5\%. (ISN = índice de suficiência de nitrogênio, dms $=$ desvio padrão médio e $\mathrm{CV}=$ coeficiente de variação).

Quando se somou produção de matéria seca da parte aérea (PMSPA) com produção de matéria seca da raiz (PMSR) foi possível obter a produção de matéria seca total (PMST), em que se observou que a testemunha do ensaio com Marandu apresentou menor PMST em relação a referência e aos tratamentos T1, T3, T4 e T5. No ensaio com Mombaça, a testemunha apresentou menor PMST em relação aos demais tratamentos devido à menor PMSR. Resultado semelhante ao observado para a relação entre a produção de matéria seca da parte aérea e de raiz (PMSPA/PMSR) dos capins Marandu e Mombaça, em que as testemunhas apresentaram maiores relações PMSPA/PMSR em relação aos demais tratamentos em função de suas menores produções de raiz. 
Os resultados relacionados à produção de matéria seca de ambas as forrageiras avaliadas demonstraram que a PMSR foi mais sensível à falta adubação nitrogenada do que a PMSPA, principalmente para o capim Marandu. Sarmento et al. (2008), avaliando o efeito da adubação nitrogenada $(0,150,300$ e $450 \mathrm{~kg} / \mathrm{ha})$ sobre o sistema radicular do Panicum maximum Jacq. cv. IPR-86 Milênio, sob pastejo, verificaram que doses menores de $\mathrm{N}$ proporcionam maior volume de raízes, enquanto doses altas resultaram em menor produção de raízes, contrariando os resultados encontrados no presente estudo. Embora as informações sobre o crescimento de raízes na literatura sejam mais escassas em relação àquelas disponíveis para a parte aérea, existem trabalhos que observaram aumento na produção de matéria seca tanto de parte aérea quanto de raiz com o aumento das doses de $\mathrm{N}$.

Maranhão et al. (2009) avaliando a produção de matéria seca da parte aérea (PMSPA) e da raiz (PMSR) do capim Marandu submetido a quatro doses de nitrogênio $(0,75,150$ e $225 \mathrm{mg}$ de $\mathrm{N} / \mathrm{dm}^{3}$ ), observou que a melhor dose de $\mathrm{N}$ em relação a PMSPA e a PMSR foi a $162,0 \mathrm{mg}$ de $\mathrm{N} / \mathrm{dm}^{3}$. A PMSR atingiu o máximo com aproximadamente $135 \mathrm{mg} \mathrm{de} \mathrm{N} / \mathrm{dm}^{3}$, a partir desse valor, houve decréscimo na PMSR, enquanto a PMSPA atingiu um máximo em torno de $180 \mathrm{mg}$ de $\mathrm{N} / \mathrm{dm}^{3}$; a partir deste ponto, a produtividade praticamente não se alterou.

No presente estudo, as semelhanças observadas em termos de altura e produção acumulada de MS da parte aérea podem ter sido decorrentes tanto do adequado ajuste no fornecimento de $\mathrm{N}$ realizado com o monitoramento do ISN quanto ao fato dessas variáveis terem sido avaliadas em ensaio de curta duração. Nesse caso, a matéria orgânica do solo pode ter sido capaz de reduzir o impacto da falta de $\mathrm{N}$ proveniente do fertilizante nas parcelas das testemunhas. Embora a dinâmica da matéria orgânica no solo seja bastante complexa. A liberação ou indisponibilização no $\mathrm{N}$ para as plantas, por exemplo, depende das condições do ambiente e de características do material orgânico do solo (Monteiro et al., 2002).

No entanto, em ensaios de médio ou longo prazo, pode ser que seja possível detectar diferenças entre as parcelas não adubadas e adubadas decorrentes da diminuição da produção de matéria seca de raiz, já que a produtividade da parte aérea é reflexo do que acontece com o sistema radicular, pois ambos interagem. Logo, qualquer fator que limite o crescimento de raízes pode prejudicar a produção de massa seca da planta forrageira (Giacomini et al., 2005).

Considerando a eficiência de conversão do nitrogênio fertilizante (ureia) em matéria seca de parte aérea de forragem, observou-se que entre os tratamentos ISN do capim Marandu, os que receberam as maiores doses de nitrogênio, ao longo do período experimental foram o $\mathrm{T} 1 \mathrm{com}$ $2,52 \mathrm{~g}$ de ureia/ vaso, equivalente a $160,00 \mathrm{~kg}$ de $\mathrm{N} / \mathrm{ha}$, superando a dose aplicada nos vasos referência; e o T3 com 1,89 g de ureia/vaso, equivalente a 120,00 kg de N/ha. Já para o capim Mombaça, os tratamentos com a maior dose de nitrogênio foram $\mathrm{T} 1$ e $\mathrm{T} 2$, em que ambos receberam $1,89 \mathrm{~g}$ de ureia/vaso, equivalente a $120,00 \mathrm{~kg}$ de N/ ha.

Nesse sentido, os tratamentos mais eficientes foram os que receberam menor quantidade de nitrogênio aplicado em cobertura, comportamento observado nos dois capins (Tabela 4). Corroborando com os resultados encontrados por Mello et al. (2008) que avaliou a eficiência de conversão aparente de nitrogênio (ECAN) em pastagem estabelecida com capim Mombaça, submetida a diferentes doses de nitrogênio $(0,100$, 300 e $500 \mathrm{~kg} / \mathrm{ha}$ ), observando que doses crescentes de nitrogênio causaram significativa produção de massa seca, porém diminuíram a ECAN, ocasionando perdas de nitrogênio do ecossistema da pastagem para o ambiente.

De acordo com Mello et al. (2008), a eficiência de conversão do nitrogênio em forrageiras, principalmente em espécies de Panicum maximum, é relatada na literatura, com variações de 10 a $90 \mathrm{~kg}$ de matéria seca produzida por $\mathrm{kg}$ de nitrogênio aplicado.

No caso do capim Marandu, os tratamentos que se destacaram, produzindo maiores quantidades de capim com menor dose de nitrogênio foram: T2, T4 e T5. Já para o capim Mombaça, os tratamentos mais eficientes foram T3, T4 e T5 (Tabela 4). Desse modo, os tratamentos mais eficientes comuns aos dois capins avaliados são T4 e T5 que correspondem aos índices de suficiência de nitrogênio (ISN) 0,87 e 0,83 , respectivamente. 
Tabela 4. Eficiência de conversão do nitrogênio em matéria seca dos capins Marandu e Mombaça.

\begin{tabular}{|c|c|c|c|c|c|c|}
\hline \multirow{2}{*}{ Tratamento } & \multicolumn{3}{|c|}{ Marandu } & \multicolumn{3}{|c|}{ Mombaça } \\
\hline & $1^{\circ}$ Corte & $2^{\circ}$ Corte & Média & $1^{\circ}$ Corte & $2^{\circ}$ Corte & Média \\
\hline Referência & $26,55 \mathrm{~b}$ & $14,20 \mathrm{~b}$ & $27,48 \mathrm{bc}$ & $27,99 \mathrm{~b}$ & $13,62 \mathrm{~b}$ & $27,62 \mathrm{~b}$ \\
\hline 1 (ISN: 0,96) & $14,12 \mathrm{c}$ & $11,25 \mathrm{c}$ & $21,85 \mathrm{c}$ & $24,73 \mathrm{~b}$ & $14,22 \mathrm{~b}$ & $30,71 \mathrm{~b}$ \\
\hline 2 (ISN: 0,93) & $44,28 \mathrm{a}$ & $22,15 \mathrm{a}$ & $44,29 \mathrm{a}$ & $24,29 \mathrm{~b}$ & $15,57 \mathrm{~b}$ & $31,76 \mathrm{~b}$ \\
\hline 3 (ISN: 0,90) & $22,64 \mathrm{~b}$ & $14,38 \mathrm{~b}$ & $29,47 \mathrm{~b}$ & $47,54 \mathrm{a}$ & $25,12 \mathrm{a}$ & $48,89 \mathrm{a}$ \\
\hline 4 (ISN: 0,87) & $44,75 \mathrm{a}$ & $21,54 \mathrm{a}$ & 43,92 a & $50,73 \mathrm{a}$ & $22,21 \mathrm{a}$ & $47,57 \mathrm{a}$ \\
\hline 5 (ISN: 0,83) & $47,29 \mathrm{a}$ & $21,84 \mathrm{a}$ & $45,48 \mathrm{a}$ & $47,51 \mathrm{a}$ & $23,18 \mathrm{a}$ & $46,93 \mathrm{a}$ \\
\hline $\mathrm{dms}$ & 8,27 & 2,18 & 5,87 & 5,49 & 5,71 & 6,77 \\
\hline $\mathrm{CV} \%$ & 11,07 & 5,53 & 7,38 & 6,59 & 13,39 & 7,75 \\
\hline
\end{tabular}

Médias seguidas de letras iguais não se diferem pelo teste de Tukey a 5\%. (ISN = índice de suficiência de nitrogênio, dms $=$ desvio padrão médio e $\mathrm{CV}=$ coeficiente de variação).

\section{Conclusões}

O uso do clorofilômetro portátil é adequado para o monitoramento do teor de clorofila dos capins Marandu e Mombaça cultivados em vasos e submetidos a diferentes estratégias de adubação nitrogenada com ureia em ciclos de crescimento de 51 e 43 dias. O ajuste da adubação nitrogenada com base no Índice de Suficiência de Nitrogênio (ISN) dos capins Marandu e Mombaça permitiu que ambas as forrageiras expressassem de forma semelhante em termos de altura de corte e produção acumulada de matéria seca de parte aérea, porém a produção de raiz foi menor quando os capins não foram adubados.

Considerando a eficiência de conversão do nitrogênio em matéria seca assim como as demais análises realizadas (altura, produção de matéria seca da parte aérea e de raiz), pode-se concluir que os índices de suficiência de nitrogênio (ISN) 0,87 e 0,83 são os mais indicados para manejo da adubação nitrogenada utilizando medidor portátil do teor clorofila foliar das forrageiras Brachiaria brizantha cv. Marandu e Panicum maximum cv. Mombaça nas condições de solo e clima em que esse estudo foi desenvolvido.

\section{Referências bibliográficas}

Abreu, J. B. R. \& Monteiro, F. A. (1999). Produção e nutrição do capim Marandu em função de adubação nitrogenada e estádios de crescimento. Boletim de Indústria Animal, 56, 137-146.

Barbieri, I., Montossi, F., Viñoles, C. \& Kenyon, P. R. (2012). Impact of wool stubble depth after mid pregnancy shearing on Corriedale ewe and lamb performance. Small Ruminant Research, 107, 111-116.

Barbieri Junior, É., Rossiello, R. O. P., Silva, R. V. M. M., Ribeiro, R. C. \& Morenz, M. J. F.
(2012). Um novo clorofilômetro para estimar os teores de clorofila em folhas do capim Tifton 85. Ciência Rural, 42, 2241-2245.

Benettt, C. G. S., Yamashita, O. M., Koga, P. S. \& Silva, K. S. (2008). Resposta da Brachiaria brizantha cv. Marandu a diferentes tipos de adubação. Revista de Ciências AgroAmbientais, 6, 13-20.

Bullock, D. G. \& Anderson, D. S. (1998). Evaluation of the Minolta SPAD-502 chlorophyll meter for nitrogen management in corn. Journal of Plant Nutrition, 21, 741-755.

Costa, K. A. P., Faquin, V., Oliveira, I. P., Araújo, J. L. \& Rodrigues, R. B. (2008). Doses e fontes de nitrogênio em pastagem de capim-marandu: II-nutrição nitrogenada da planta. Revista Brasileira de Ciência do Solo, 32, 1601-1607.

Dias Filho, M. B. (2011). Os desafios da produção animal em pastagens na fronteira agrícola brasileira. Revista Brasileira de Zootecnia, 40, 243-252.

EMBRAPA. (2006). Sistema brasileiro de classificação de solos.

Francis, D. D. \& Piekielek, W. P. (1999). Assessing crop nitrogen needs with chlorophyll meters. Site-Specific Management Guidelines, Potash \& Phosphate Institute. SSMG-12. Reference, 12, 1-4.

Giacomini, C. A. M., Mattos, W. T., Mattos, W. B., Werner, J. C., Cunha, E. A. \& Carvalho, D. D. (2005). Crescimento de raízes de capins Aruana e Tanzânia submetidos a duas doses de nitrogênio. Revista Brasileira de Zootecnia, 34, 1109-1120.

Guimarães, M. M. C., Matsumoto, S. N., Figueiredo, M. P., Cruz, P. G. \& Araújo, G. S. (2011). Estimativa da composição química do Capim Braquiária cv. Marandu por meio de um clorofilômetro portátil. Revista Brasileira de 
Tecnologia Aplicada nas Ciências Agrárias, 4, 85-98.

Köppen, W. \& Geiger, R. (1928). Klimate der Erde. Gotha: Verlag Justus Perthes. Wall-map $150 \mathrm{~cm} \times 200 \mathrm{~cm}$.

Maranhão, C. M. A., Silva, C. C. F., Bonomo, P. \& Pires, A. V. (2009). Produção e composição bromatológica de duas cultivares de braquiária adubadas com nitrogênio e sua relação com o índice SPAD. Acta Scientiarum Animal.Sciences, 31, 117-122.

Martha Júnior, G. B., Alves, E. \& Contini, E. (2012). Land-saving approaches and beef production growth in Brazil. Agricultural Systems, 110, 173-177.

Mello, S. Q. S., França, A. F. d. S., Lanna, A. C., Bergamaschine, A. F., Klimann, H. J., Rios, L. C. \& Soares, T. V. (2008). Adubação nitrogenada em capim-mombaça: produção, eficiência de conversão e recuperação aparente do nitrogênio. Ciência Animal Brasileira, 9, 935-947.

Monteiro, H. C. F., Cantarutti, R. B., Nascimento Junior, D., Regazzi, A. J. \& Fonseca, D. M. (2002). Dinâmica de Decomposição e Mineralização de Nitrogênio em Função da
Qualidade de Resíduos de Gramíneas e Leguminosas Forrageiras1. Revista Brasileira de Zootecnia, 31, 1092-1102.

Pariz, C. M., Andreotti, M., Bergamaschine, A. F., Buzetti, S., Costa, N. R. \& Cavallini, M. C. (2011). Produção, composição bromatológica e índice de clorofila de braquiárias após o consórcio com milho. Archivos de zootecnia, 60, 1041-1052.

Werner, J. (1986). Adubação de pastagens. Nova Odessa: Instituto de Zootecnia, 129-156.

Wood, C. W., Reeves, D. W. \& Himelrick, D. G. (1993). Relationships between chlorophyll meter readings and leaf chlorophyll concentration, $\mathrm{N}$ status, and crop yield: a review. Procedings Agronomy Society of New Zeland.

\section{Article History}

Received 03 August 2016

Accepted 26 August 2016

Available on line 21 October 2016

License information: This is an open-access article distributed under the terms of the Creative Commons Attribution License 4.0, which permits unrestricted use, distribution, and reproduction in any medium, provided the original work is properly cite 